\title{
A Cyber-Training \& Education Model for Tug-barge Operators
}

\author{
Eun-Bang Lee* · Jong-Hwui Yun** • † Tae-Gweon Jeong \\ *, ** Department of Maritime Police Science, Korea Maritime University, Busan 606-791, Republic. of Korea \\ + Division of Navigation Sciences, Korea Maritime University, Busan 606-791, Republic. of Korea
}

\begin{abstract}
The purpose of this study was to create a cyber-training \& education program in response to the needs of skippers and crews operating tug-barges within Korean coastal waters and the rapid changers in this industry. Skippers and crews are inclined to operate tug-barges on the basis of experience rather than information. It is not easy to provide useful information whenever they want or to drill them in safety management skills, because of their passive attitude toward education and the few opportunities that exist. In order to increase educational opportunities, efficiency and motivation, the authors have developed this program which consists of a 'tug bridge resource management module, risk perception training module, accident case module, operating module and navigation module', and are hoping that this program will enhance and strengthen all tug-barge operations. We are also putting all our energies into designing up to date animation programs and developing new scenarios concerning the method of evaluation and certification distribution.
\end{abstract}

Key words : tug-barge, cyber training, education program, human error, bridge resource management, risk perception training, accident case module, operating module, navigation module

\section{Introduction}

In the aftermath of the December 7, 2007 crude oil spillage between the oil tanker 'Hebei Spirit' and the 'Samsung No.1' crane barge, there is an increased interest in the safety and vulnerability of the tug-barge industry. Accidents like collision, capsize and grounding concerning tug-barges stood at five percent of the total accidents in Korean coastal waters(KMST, 2008). The causes of these accidents can be contributed to the lack of knowledge and negligence of navigational rules, poor awareness and so on. As well as the recently increased tug-barge traffic become heavier due to the transportation of sand cargo, large materials used in harbor construction and offshore structures.

Human error is the most prominent cause of marine casualties. Most of which occur in situation of contingency and maneuvering under adverse circumstance. It is at these times and in these places that tug-barge staff members have a greater workload. The 3Es (Education, Engineering, Enforcement) are referred to as a countermeasure to prevent any marine traffic accidents(Kitakawa 1982). Although no one is denying that education is one of the best policies, it is difficult to design an appropriate program and service in which all trainees and tug-barge crews can be satisfied. As well as the limited opportunities and a passive attitude concerning the re-education are needed to change. Then both crews and owners cannot be expect results and are reluctant to invest time and money in receiving and providing these educational programs. Under these circumstances, the vicious cycle continues in which poor education results in poor education programs. Therefore, skippers are inclined to operate their tug-barges on the basis of experience rather than on information and knowledge.

In order to reduce the risk of casualties through the education, it is necessary that a new paradigm be designed toward re-education in which all tug barge crews willingly participate in the classes and all owners believe in this theory. In this paper, cyber-training \& education programs intend to the needs of skippers and crews engaged in towing operations and the coastal traffic, which is changing at a rapid pace.

\section{Educational environment analysis on tug-barge operation}

\subsection{State of tug-barge}

Domestic tug-barges have been operated in the three sections: maritime construction, coastal transportation and

\footnotetext{
* Representing author, eunbang@hhu.ac.kr, 051)410-4236

** jhyun@hhu.ac.kr, 051)410-4279

+ Corresponding author, tgjeong@hhu.ac.kr, 051)410-4246
} 
maritime crane. They play a key role in carrying offshore structures and plant material and equipment for port development and reclamation, building materials for bridges, and dredging equipment and blocks for shipbuilding. Table 1 shows the numbers of tugs and barges registered and companies operating them(MLTM, 2008). Many of the smaller companies, which have less than three tugs or barges on average, run their business under over competition.

Table 1 Tugs and barges that are registered.

\begin{tabular}{|c|c|c|c|c|}
\hline \multicolumn{2}{|c|}{ type } & company & vessel & G/T \\
\hline \hline \multirow{7}{*}{ barge } & sand & 15 & 128 & 219,258 \\
\cline { 2 - 5 } & steel product & 3 & 26 & 30,895 \\
\cline { 2 - 5 } & chemicals & 0 & 1 & 401 \\
\cline { 2 - 5 } & oil product & 2 & 17 & 7,788 \\
\cline { 2 - 5 } & waste matter & 1 & 7 & 11,036 \\
\cline { 2 - 5 } & general cargo & 26 & 191 & 254,776 \\
\cline { 2 - 5 } & $\begin{array}{c}\text { construction } \\
\text { equipment }\end{array}$ & 109 & 476 & 228,836 \\
\cline { 2 - 5 } & subtotal & 156 & 846 & 753,017 \\
\hline \multirow{4}{*}{ tug } & tug boat & 236 & 635 & 58,969 \\
\cline { 2 - 5 } & subtotal & 236 & 635 & 58,969 \\
\hline
\end{tabular}

\subsection{Education attitude of skipper and crew}

In order to investigate the attitude of skippers and crews, a questionnaire was compiled between August and December 2008. Seventy one crew members were required to answer the question "Do you need any educational programs on tug-barge operations ?" More than $50 \%$ fall

Table 2 Need of education

\begin{tabular}{c||c|c|c|c|c} 
need & yes & no & no idea & no answer & total \\
\hline \hline person & 29 & 18 & 17 & 7 & 71 \\
\hline ratio(\%) & 40.85 & 25.35 & 23.94 & 9.86 & 100
\end{tabular}

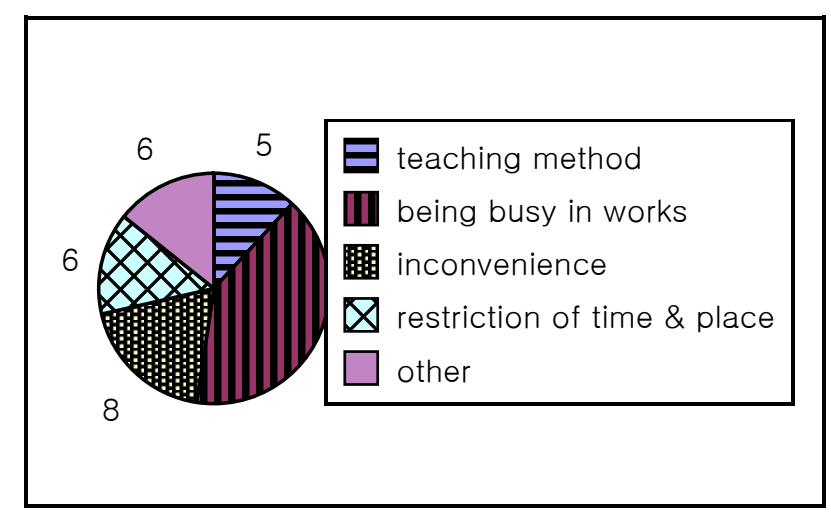

Fig. 1 Negative reasons on education into in a negative category toward the need of re-education. In table 2 . the reasons shows why they have this negative attitude towards the need of re-education and are displayed in Fig. 1. It was found that workload and inconvenience towards attending an educational program acted as a brake on the motivation for $\mathrm{re}^{-}$education.

\subsection{A new paradigm to respond educational requirements}

Most of the tug-barges are operated by small business. And crew members have gained their knowledge through long sea careers and are operating their tug-barges on the basis of experience rather than on the educational knowledge and information that is available to them. Since they are getting order, they are reluctant to attend an education program, because of the long distances they have to travel and the lack of interest they have in re-education.

Therefore, with the need of re-education concerning new towing techniques, new up-to-date training methods and distinctive programs should be designed. Bringing together and training tug barge operators will reduce the risk of accidents with the help of computer based, cyber, self-triggering and object oriented training methods. Fig. 2 shows the concept of educational programs for tug-barge operators. This training program consist of a tug-barge bridge resource management module, risk perception training module, accident case module, operating and navigational module and so on.

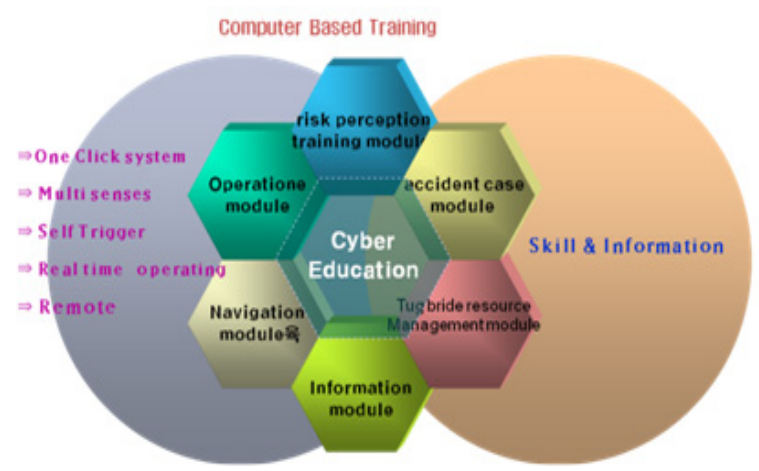

Fig. 2 A concept of a re-education program involving tug-barges

\section{Cyber class on tug-barges}

\subsection{Cyber class}

In cyber classes, crews can gain new knowledge and individually participate in drills by triggering on screen icons. In addition new data and information can be 
exchanged anywhere, anytime while on line. If this scenario with the modules that are provided, this knowledge is expected to play a role of providing a new paradigm for re-education for tug-barge operators. They can also participate in the classes concerning risk perception, operating and navigational training as well as tug-barge bridge resource management classes with accident case studies with multi-senses.

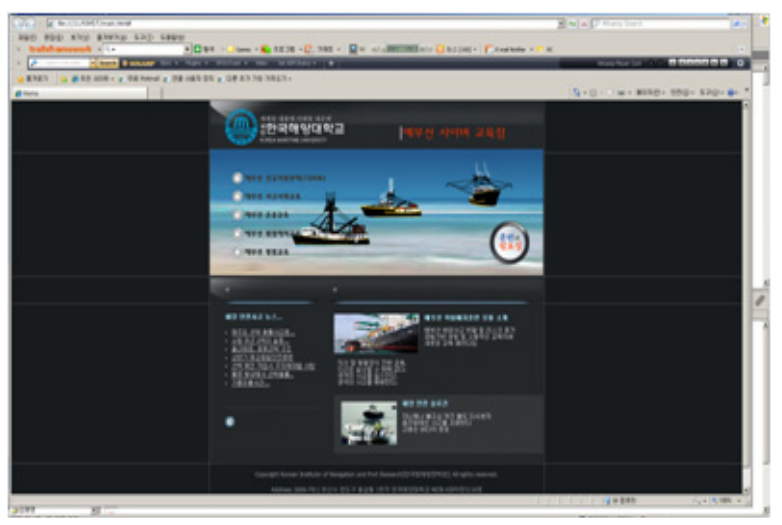

Fig. 3 Cyber class for tug-barge operators $\cdots$

\subsection{Risk perception training module}

There are many theories when trying to explain why people calculate the different dangers associated with risks. The purpose of this training is to determine whether hazards are perceived to pose a risk to tug-barge operation. Hazards like bridges, fishing boats, human error, narrow channels, towing lines, waves and winds are listed.

The first step when using six scenarios concerning the main causes of accident for risk perception training like those in Fig. 4, four questions are asked using different scenarios as followed:

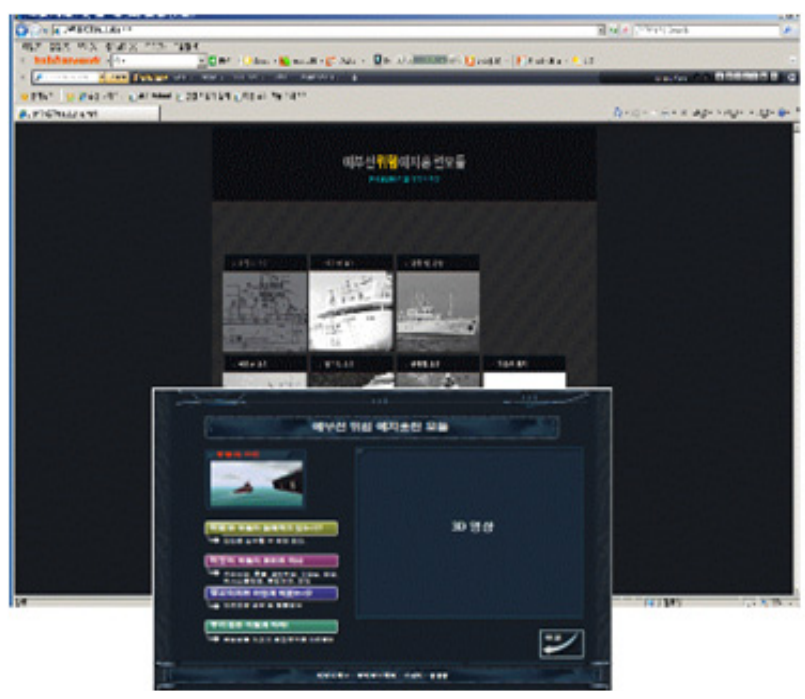

Fig. 4 Risk perception training module
(1) What is a potential hazards?

(2) What level of danger is associated with the hazards?

(3) What ideas do you have in reducing the risk?

(4) What counter measure do you have in preventing casualties?

In the second step, after one sense the risk on scenarios, he can compare standard answers with his answers by clicking the icons respectively.

\subsection{Operating training module}

In this module tug-barges operate in different scenario and apply different hazards according to their towing patterns, cargo being transported and work they're engaged in. Crews can then acquire not only the know-how and technical details for operating a tug-barge, but also accumulate various experience in the field. These field situation and hazards are related with accidents that have already occurred in the operation of a tug-barge and are included in training materials(Noble Denton, 2003). This module is expected to help tug-barge operator operate their tug-barges more efficiently and reduce the risk of accidents using the right procedures.
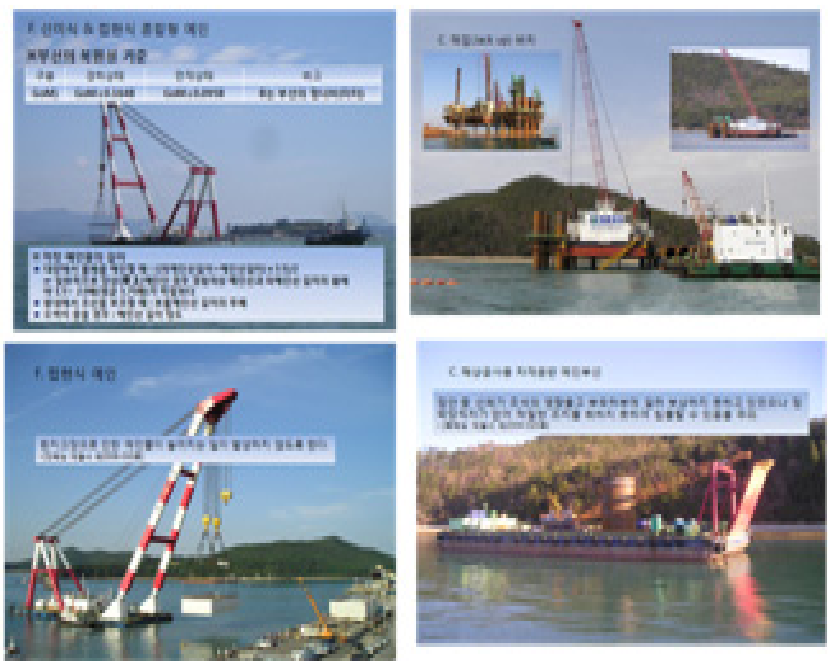

Fig. 5 Field training module in operating tug-barge

\subsection{Navigation training module}

Tug-towing modes are handled in three different ways, where barges are being towed astern, towed alongside or pushed by tugs. Conventional barges are towed astern by a tug and are propelled by the force generated by the tug's engines, using a tow line or cable that is connected to the barge bow(Hansen, 2002; Reid, 2003; US Navy 2002). The direction of movement is to a large extent, determined by 
the direction in which its bow is pulled by this force, But there are also other factors that can effect the direction of their movement. Some barges are directionally unstable, and tend to either yaw or to sheer and generally are restricted in their movements. This is also a contributing factor to many of the accidents involving barges and it is compulsory when handle a tug connected to a barge to consider all towing maneuvers.

The final outcome of any marine operation usually depends upon the capability of tug-barge crew and this is especially true in towing industry, where only a few crew members are required, when dealing with the safe navigation of a tug-barge. The training module helps operators navigate tug-barges according to international regulations for the prevention of collision at sea. Fig. 6 shows navigation rules in several situations and are displayed schematically for full understanding.

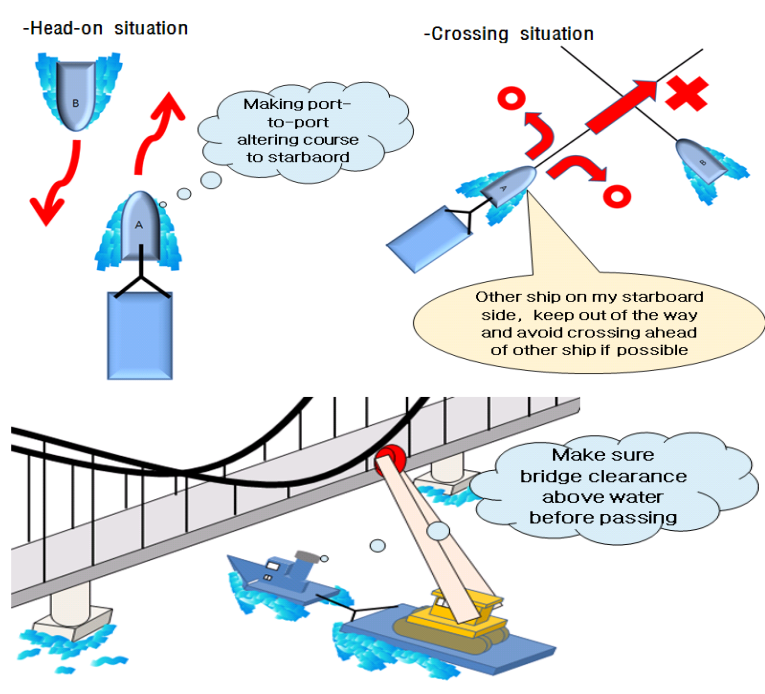

Fig. 6 A sample of steering and sailing rule training
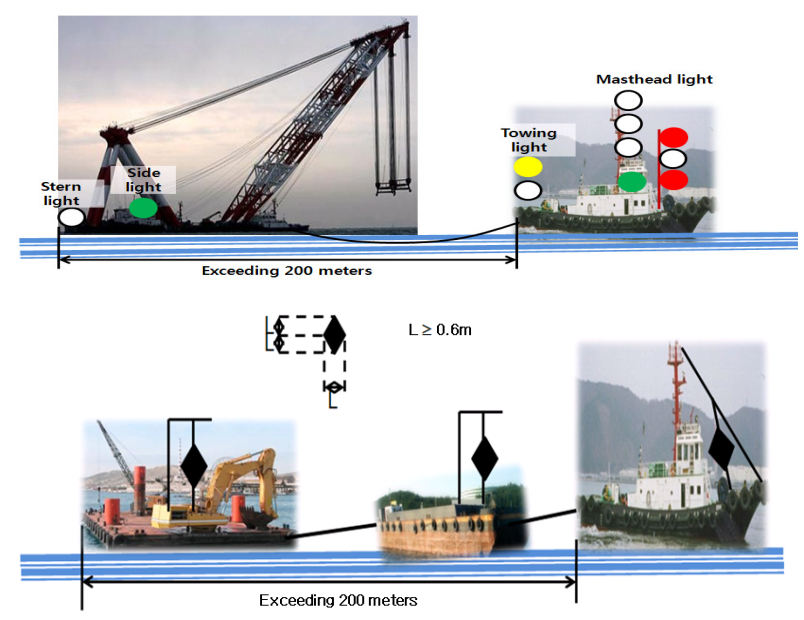

Fig. 7 A sample material for training lights and shapes of tug-barge
Fig. 7 shows how to exhibit lights and shapes of a tug-barge. In this module, tools are used to help you understand and identify a vessel situation by the lights and shapes.

\section{Behavior pattern training}

\subsection{Tug-barge bridge resource management}

Human error has long been recognized as the most prominent cause of tug-barge accidents, including collision and grounding(SAS, 2007). Most of these accidents occur in restricted waters near port entrances, and where traffic converges. It's only human nature for crews to make mistakes, when dealing with communicational, organizational, psychological, physical and physiological factors. Weakness in bridge organization and management are other causes of marine accidents and casualties.

Tug-barge bridge resource management(TBRM) can reduce the risk of marine casualties by helping tug bridge crews to anticipate and correctly respond to dangerous situation. TBRM uses effective management tool that utilize all resources of both human and information available to bridge teams for the safe completion of tug-barge operation and are modified like Fig. 8. It is one of most effective methods for training, using standard sequences of ship handling and seamanship, which are seldom required in other sectors.

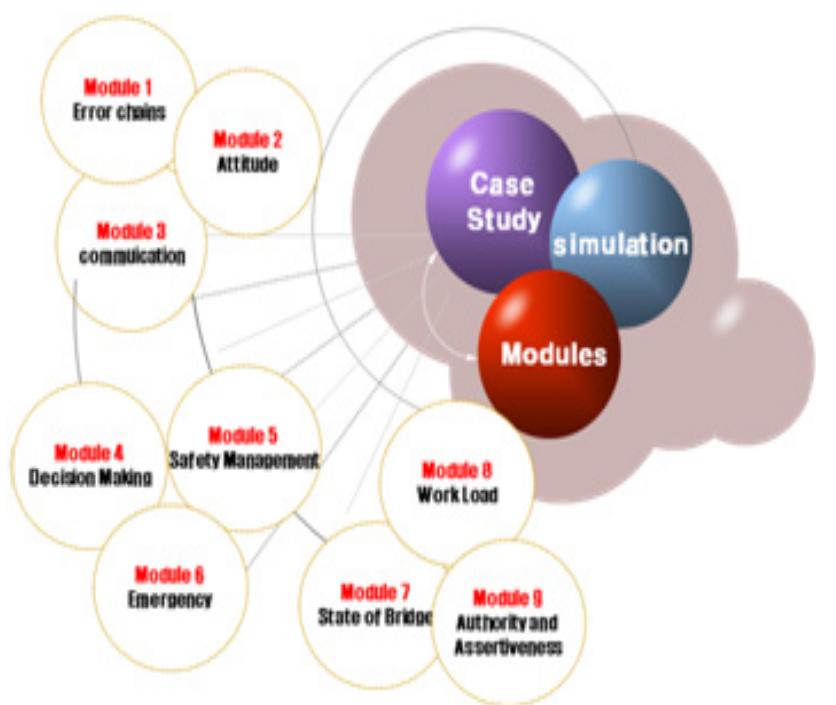

Fig. 8 Design of tug-barge bridge resource management

\subsection{Modules for TBRM}

1) Error chain module

This module is designed to understand the errors that 
has long been recognized as the most prominent cause of tug-barge accidents, such as groundlings and collisions. Fig. 9 shows human error chains

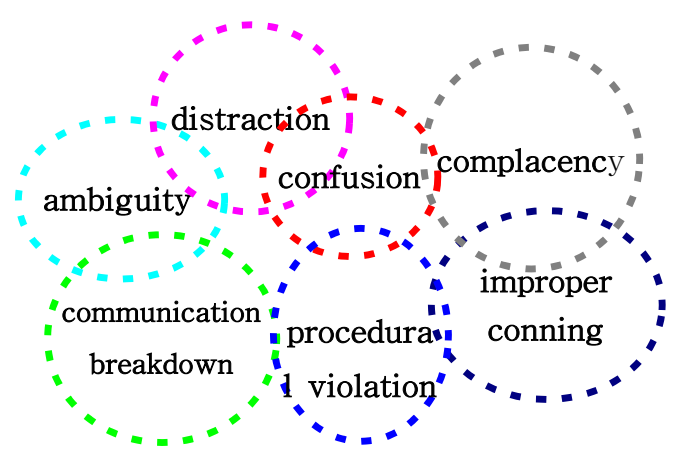

Fig. 9 Human error chains

\section{2) Attitude module}

This module is designed to explain the reason for internal and external errors and to learn from human errors and recognize underlying causes of these accidents.

\section{3) Communication module}

This module is designed to understand the principles of good bridge communication: setting the climate, interactive, closed loop and recognize the importance of briefings and de-briefings.

\section{4) Decision making module}

This module is designed to understand the factors affecting judgement, decision making and how hidden pressure can negatively influence them.

\section{5) Safety management module}

This module is designed to understand the risk management and to recognize risk based decision making.

6) Emergency module

This module is designed to understand types of emergency and a strategy for dealing with emergency situations

\section{7) State of bridge module}

This module is designed to understand the factors that have major impact on the state of the bridge and recognize the six states of a bridge. They are as followed; +1 optimum, +2 concerned, +3 alarmed, -1 bored, -2 inattentive and -3 inattentive at a critical phase.

\section{8) Workload module}

This module is designed to recognize the whole range of workloads. They are as followed; underload, normal, high and overload.

\section{9) Authority and assertiveness module}

This module is designed to understand the need for a balance between authority and assertiveness and to recognize the possible reasons and the dangers of these extreme groupings.

\subsection{Case study module of accident}

The accident case studies are effective for determining the reasons why accidents occur and finding a countermeasure in preventing further casualties. Three types of information-oriented cases may be distinguished: extreme or deviant cases, critical cases and paradigmatic cases. These accidents have been occurred in Korean waters for past ten years and are analyzed and divided into three categories: collision, grounding and environment pollution.

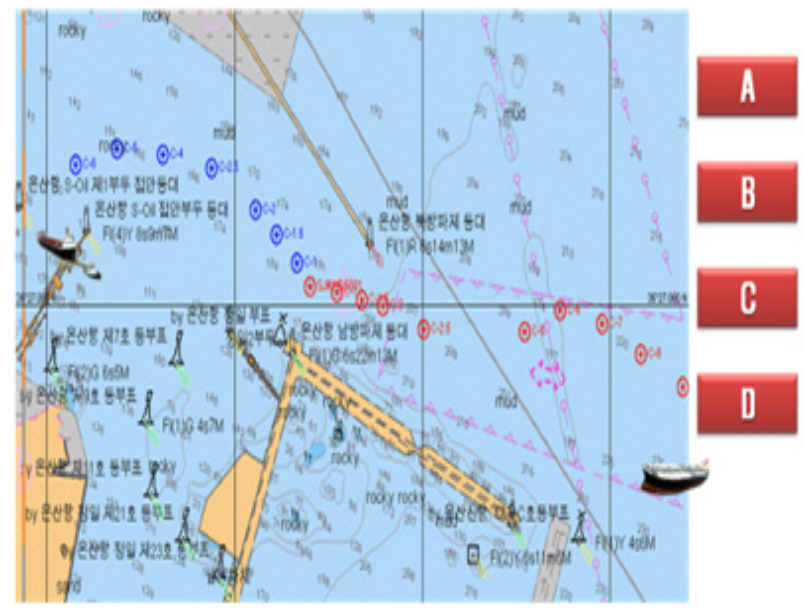

Fig. 10 The scene of accident case on paper chart

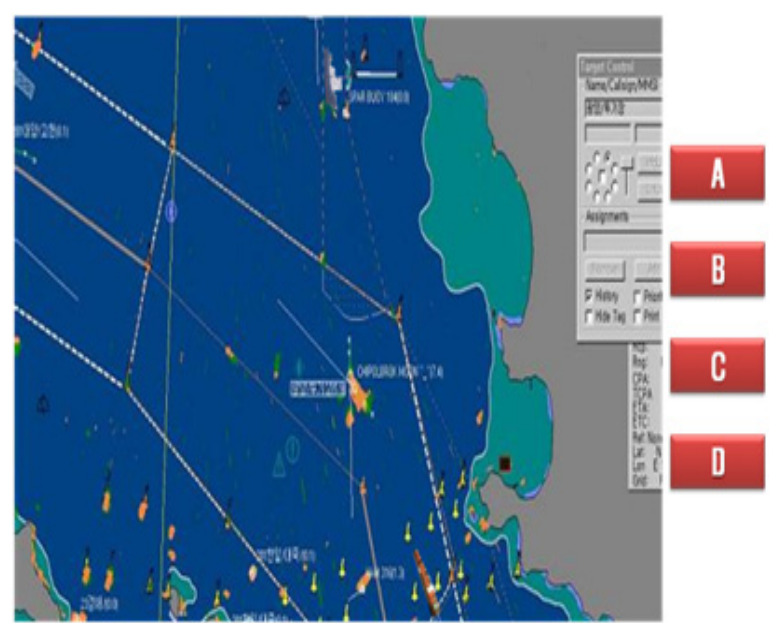

Fig. 11 The scene of accident case on ECDIS 
This module also look at six tug-barge accidents, which have caused widespread damage and are selected as case studies. These accidents are display as a dynamic motion on PPT skin, and can be operated and triggering by all participants, when selecting on screen icons: A, B, C or D, with step by step instructions: (A) Causes, (B) Lessons on accidents, (C) Skills and (D) Knowledge, which crews should be well acquainted with and can be seen on paper chart in Fig. 10 and on ECDIS in Fig. 11.

\section{Discussions and concluding remarks}

These results and statistics have been analyzed concerning tug-barge accidents over the past ten years and imply that the human error is the main cause for marine casualties rather than mechanical failure. In order to reduce further tug-barge incidents, the human related factors should be considered. Educational methods and the environment in which tug-barge operate were also reviewed Along with the concern and attitudes towards re-education in the tug-barge industry by crew members and managers, and these findings were established using questionnaires.

Out of regards for operator's needs and the circumstance in which coastal traffic is changing, a cyber-training \& education model for tug-barge operating spaces was developed. This consists of a tug-barge resource management module, risk perception training module, accident case study module, operation training module and navigation training module. Without the restriction of time and place, tug-barge operators can now contribute to cyber classes in order to gain training in the standard sequences on the handling of tug-barges and seamanship. In the long run, it is expected that these programs and cyber

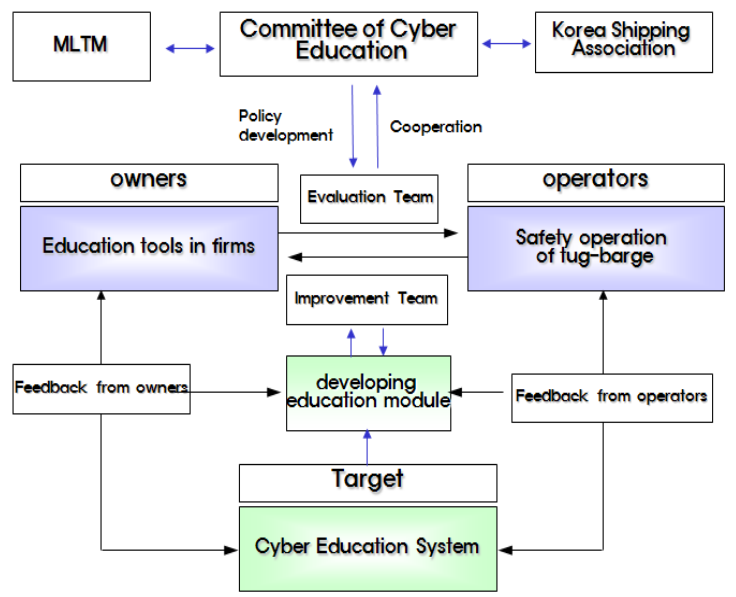

Fig. 12 The system of cyber education on tug-barge classes will address any problems concerning tug-barge operations in the future. In addition, the system concept of cyber education as shown in Fig. 12 has been compiled to improve modules and to follow field environment regulations as well as to continuously evaluate and gain feedback from all participants.

We will make an effort to review the re-educational process and fine alternative ways of improving this industry. We are putting all our energies into designing visual animation, developing new scenarios and working out a way for evaluation and certification distribution.

\section{Acknowledgements}

The results of this research were parts of the project called 'the Development of Safe Operation Model of Tug-Barge based on Advanced Technology of Vessel Handling Method' and founded by a grant from 'The Development Program for Ship Safety \& Technology' funded by the Ministry of Land, Transport and Maritime Affairs. This paper was presented in 'Asia Navigation Conference 2009' held in Shizuoka, Japan, in November, 2009.

\section{References}

[1] Hensen H. F.(2003), "Tug Use in Port, 2nd edition", Nautical institute, pp. 43-67.

[2] Jeong, T.G., Lee, E.B and Kim, J.R(2.009),"A Study on the Development of a Cyber-Training \& Education Module for Tug/Barge Skippers and Crew", Asia Navigation Conference 2009 Proceedings, pp.130-135.

[3] Kitakawa T.(1982), "Basic Safety Engineering, Kaibundo", Tokyo, pp. 23-24.

[4] Korean Maritime Safety Tribunal(2008), Marine Accidents Statistics, http://www.kmst.go.kr.

[5] Ministry of Land, Transport and Maritime Affairs(2008), "Shipping Registry of Towing Vessel", pp. 7-10.

[6] Noble Denton(2003), "Guidelines for the Approval of Towing Vessels", pp. 7-10.

[7] Reid, G. H. (2004) : "Primer of Towing", 3rd edition, Cornell Maritime Press, Maryland, pp. 94-109.

[8] SAS Flight Academy(2007), "Bridge Resource Management", edition 6, pp. 1.1-12.4.

[9] U. S. $\operatorname{Navy}(2002)$ : "U. S. Navy Towing Manual", pp. 2.1-2.7.

Received 26 January 2010

Revised 7 April 2010

Accepted 14 April 2010 